JARES, Vol. 4 No. 1 March, 2019; p-ISSN: 2502-826X; e-ISSN: 2503-1163

Copyrights@ Balitar Islamic University, Blitar, Indonesia;

https://ejournal.unisbablitar.ac.id/index.php/jares

Citation: Habibulloh, M., \& Sifaunajah, A. (2019). IMPLEMENTATION OF FOUR

BASIC PHYSICAL LAWS IN THE ADVENTURE GAME "ESCAPE LAND\&quot; JARES (Journal of Academic Research and Sciences), 4(1), 48-54. https://doi.org/10.30957/jares.v4i1.689

\title{
IMPLEMENTATION OF FOUR BASIC PHYSICAL LAWS IN THE ADVENTURE GAME "ESCAPE LAND"
}

\author{
Mohammad Habibulloh \\ Information Systems Program, Faculty of Information Technology, University of KH. A. \\ Wahab Hasbullah, Jombang East Java, Indonesia, e -mail : habibassa19@gmail.com, \\ Agus Sifaunajah \\ Information Engineering Program, Faculty of Information Technology, University of KH. A. \\ Wahab Hasbullah, Jombang East Java, Indonesia, e -mail : agus.syifa85@gmail.com
}

\begin{abstract}
There is no doubt that games are a big part of the technology that is experiencing rapid development. Many people think that games are only entertainment in their spare time, but during the development of technology, games are also included in the category of learning media. Games are often used as simulation media in large companies and developing companies, not only on a company scale but in education they can also use games as an alternative media for limited learning facilities, as well as tools and materials owned by these educational institutions. In this study, the author will try to make a game that functions not only as an entertainment medium but also as learning for all people, especially students in the field of science to improve skills in the field of physics. The game that the author wants to make, elements in the game are not fixated by learning like in class in general, but the author provides a challenge in the game in the form of exciting adventures so that the game players consciously or unconsciously can learn the physics of the science-packed in the game.
\end{abstract}

Keywords - Games, Game Physics, Computer Games, Construct 2, Puzzle Games, Adventure Games, Physics.

\section{INTRODUCTION}

Games have an important role in the development of increasingly rapid technology, as long as the development of game technology is not just entertainment, but also can be used as a window of information and learning media. In the learning process using game media, it will be quickly understood because of the great interest in manual learning that still uses print media. Conventional learning systems often make students saturate quickly and will eventually hinder learning, and it takes a long time to get the material learned [1]. Besides that games can be the best media when the use of teaching facilities is still limited.

Physics lessons often become frightening subjects for students. They still think that physics is difficult because it counts a lot using fairly complex formulas, and uses various symbols. Students are also required to memorize physics formulas. This causes a reduction in students' interest in learning about physics subjects. These problems usually arise because of the lack of activity of students during learning and the use of limited 
JARES, Vol. 4 No. 1 March, 2019; p-ISSN: 2502-826X; e-ISSN: 2503-1163

Copyrights@ Balitar Islamic University, Blitar, Indonesia;

https://ejournal.unisbablitar.ac.id/index.php/jares

Citation: Habibulloh, M., \& Sifaunajah, A. (2019). IMPLEMENTATION OF FOUR

BASIC PHYSICAL LAWS IN THE ADVENTURE GAME "ESCAPE LAND\&quot; JARES (Journal of Academic Research and Sciences), 4(1), 48-54.

https://doi.org/10.30957/jares.v4i1.689

infrastructure. In connection with the problems that occur in learning physics in school, according to the author, it is necessary to establish alternative learning that is suitable and able to improve the skills of thinking, problem-solving skills and can improve student learning outcomes in physics lessons.

Nowadays, computer-assisted learning media have developed in almost every subject, so the increase in media efficiency that contains elements of education is needed as an alternative and new innovation in education to facilitate the learning process [2]. The use of teaching media in the teaching and learning process can arouse the desire and interest in new learning, generate motivation and stimulation of learning activities, and even bring psychological influences to students [3]. There has been a lot of game development as alternative learning media, one example of which is the Angry Birds game that adopts the concept of physics [4].

\section{THEORETICAL BASIS}

\section{A. Physics}

Physics is a knowledge that learns about natural behavior in the scope of space and time, physics is one of the most basic sciences. Lots of games that adopt the legal concepts of physics such as the Angry Birds game, Rodrigues uses the Angry Birds game to teach the concepts of dynamics and motion kinematics with the help of images, animation, and sound [3], also in the Pinball game there are laws of gravitational force, spring force, collisions, etc.

\section{B. Physics Law}

In this study, the author uses several laws of physics including gravity, parabolic motion, magnetism, waves, spring force, collisions, etc. Parabolic motion is a motion that forms a certain angle to the horizontal plane. In friction parabolic motion ignored, and forces acting only gravity/acceleration.

Gravitational force is the attraction that occurs between all particles that have mass in the universe. The sun's gravity causes celestial objects to be in their respective orbits around the sun. Modern physics describes gravity using Einstein's Theory of General Relativity, but Newton's law of universal gravity is simpler and more accurate in most cases.

Waves are vibrations that propagate. The ideal form of a wave will follow the sinusoid movement. In addition to electromagnetic radiation, and possibly gravitational radiation, which can travel through vacuum, waves are also present in the medium (which because changes in shape can produce a spring force) where they can walk and can move energy from 
JARES, Vol. 4 No. 1 March, 2019; p-ISSN: 2502-826X; e-ISSN: 2503-1163

Copyrights@ Balitar Islamic University, Blitar, Indonesia;

https://ejournal.unisbablitar.ac.id/index.php/jares

Citation: Habibulloh, M., \& Sifaunajah, A. (2019). IMPLEMENTATION OF FOUR

BASIC PHYSICAL LAWS IN THE ADVENTURE GAME "ESCAPE LAND\&quot; JARES (Journal of Academic Research and Sciences), 4(1), 48-54.

https://doi.org/10.30957/jares.v4i1.689

one place to another without causing particles medium moves permanently, ie there is no mass transfer.

Electromagnetic Style Is a field formed by moving an electric charge (electric current) which causes a force to emerge in other moving electric charges. The quantum mechanical rotation of one particle forms an electromagnetic field and the rotation is affected by itself like an electric current.

\section{GAME}

Aside from being an entertainment medium, games can also be a medium of learning to improve one's brain development [5]. Games are multimedia games that are made as attractive as possible so that players get inner satisfaction [6], the game has a goal to achieve victory in accordance with the rules that have been set, and get awards directly when completing a challenge [7]. The types of games are known by the term genre, the genre is also referred to like the format or style of a game [5]. Style in a game can be pure one genre or mixture of several genres with the intention of making the game elements more varied and challenging.

Genre the most popular game is the genre Adventure or adventure that emphasizes the storyline and the ability to think of players in analyzing and solving puzzles using objects around them [8]. Besides, the puzzle genre is the forerunner of today's game, the puzzle is a simulation game with clear objectives that requires logic, and tactics to play it [9]. Games can be run on various platforms such as a smartphone, computer, console, etc. Computers are tools that are programmed and designed automatically to do arithmetic sequences or logical operations [10].

\section{A. Game Engine}

The game engine is software that is designed to create and develop a game [11]. Some games engine that is usually used to make games such as Macromedia Flash, Game Maker, Construct 2, Unity, Unreal Engine, and many others.

Game the Construct 2 engine is a game engine that is suitable for use by beginners because of the game the Construct 2 engine does not use a particular programming language to make a game, but only uses events that are needed to set the logic of the game that you want to make.

By using games the Construct 2 engine also makes it easy to adjust the appearance of the game because of the game the engine uses a visual drag \& drop method that makes it easy to move objects precisely and quickly. 


\section{B. Supporting Tools}

In one of the steps of making a game that is making graphics and audio in the game. For graphics creation in games, the author uses CorelDraw X7 software to create vector images such as character assets, obstacle, ground, effects, and others. And for audio making, the author uses FL Studio software to make background music and sound effects.

The author also uses additional software, namely Spriter, the software is used to create animations that are useful for beautifying the look of the game and making it more realistic.

\section{RESEARCH METHODS}

There are two methods used in making this game, namely data collection methods and system development methods.

\section{A. Method of collecting data}

In the method of data collection, the author uses the literature study method and observation. Methods of data collection by collecting literature, journals, papers and readings needed to build and develop the game "Escape Land". While the observation method is a method of collecting data by conducting research and direct review of the problems taken so that the author can find out what is needed to build the game "Escape Land".

\section{B. System Development Method}

The system development method used by the author to build the game "Escape Land" is the System Development Life Cycle (SDLC) using the Waterfall model.

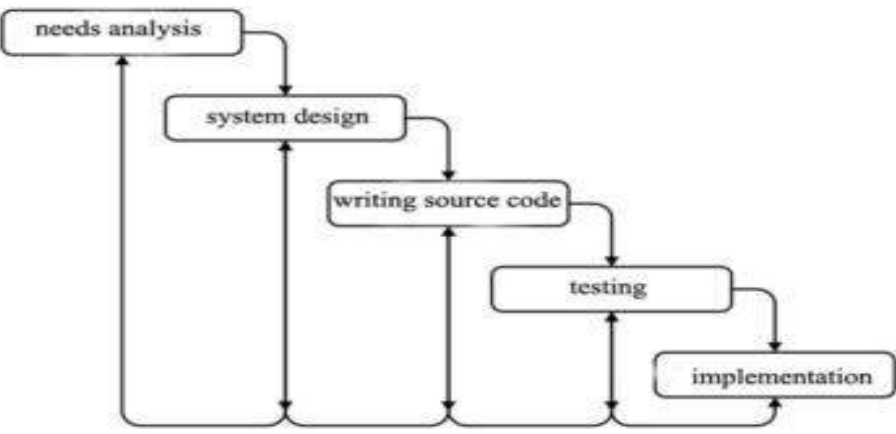

Fig. 1 SDLC Method with a waterfall model 
This SDLC model is one model that is widely used in software development, following the steps:

1) Needs analysis: the process of gathering needs is done intensively to specify the needs of the game so that the game can be understood as needed by the user.

2) System design: the process of designing data structures, game architecture, interface representation, and coding procedures that typically use Context Diagrams, Data Flow Diagrams (DFD), Entity Relational Diagrams (ERD).

3) Program Code Stage: this stage implements the design results in a form that can be read and understood by the computer. The results of this stage are computer programs according to the designs that have been made at the design stage.

4) Testing the Program: the program must be tested to ensure that all orders that have been made will be tried with certain commands, a function will produce output in accordance with the desired or not.

5) Program Implementation: after testing the program, the program can be marketed or carried out in the actual learning process.

\section{DESIGN AND IMPLEMENTATION}

\section{A. Game Design Flowchart}

Broadly speaking, the system, the design of making and developing the game "Escape Land" can be seen in the following flowchart :
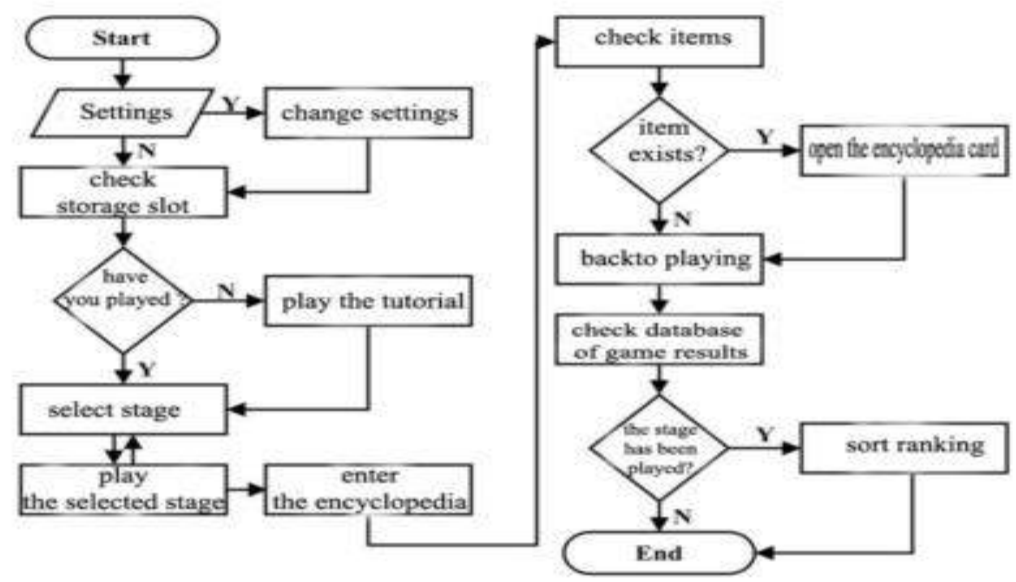

Fig. 2 Flowchart for designing the Escape Land game system 
Citation: Habibulloh, M., \& Sifaunajah, A. (2019). IMPLEMENTATION OF FOUR

BASIC PHYSICAL LAWS IN THE ADVENTURE GAME "ESCAPE LAND\&quot;. JARES (Journal of Academic Research and Sciences), 4(1), 48-54.

\section{B. Mock Up Game}

The mockup is an illustration that is used to clarify the game as to what will be made, how the game works, and what are the features in the game. Here are some mock-ups used in the Escape Land game.

1) Layout Title: the initial layout that was presented when just opening the game, the layout displays the name of the game.

\section{Escape Land}

Press Start

Fig. 3 Display the start layout

2) Layout Save Slot: layout of game data storage, make storage of new games, delete storage, and retrieve game data storage.

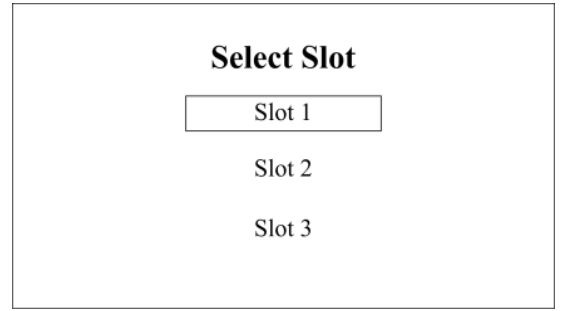

Fig. 4 Display layout select save slot

3) Layout Maps: this layout displays the levels contained in the game, and there are results of the game.

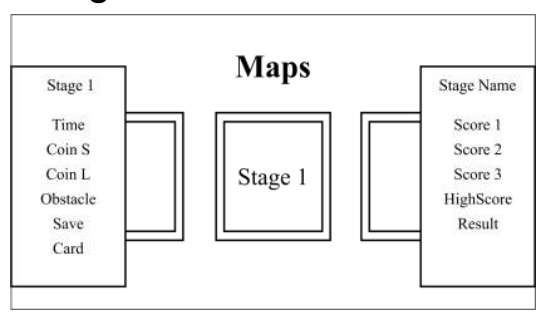

Fig. 5 Display layout maps

4) Layout Setting: This layout displays the settings options that are in the game. The following display layout settings. 
JARES, Vol. 4 No. 1 March, 2019; p-ISSN: 2502-826X; e-ISSN: 2503-1163

Copyrights@ Balitar Islamic University, Blitar, Indonesia;

https://ejournal.unisbablitar.ac.id/index.php/jares

Citation: Habibulloh, M., \& Sifaunajah, A. (2019). IMPLEMENTATION OF FOUR

BASIC PHYSICAL LAWS IN THE ADVENTURE GAME "ESCAPE LAND\&quot;. JARES (Journal of Academic Research and Sciences), 4(1), 48-54. https://doi.org/10.30957/jares.v4i1.689

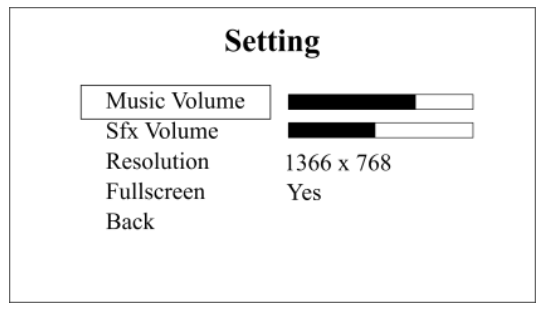

Fig. 6 Display setting layout

\section{Asset game}

1) Player: the main character is played, there are several types of players that can be selected if the game has reached the middle of the stage.

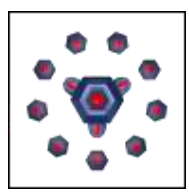

Fig. 7 The player in Escape Land game

2) Point: an item that must be obtained to fulfill the score so that it can open a closed level.

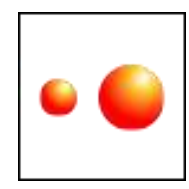

Fig. 8 item points

3) Tilemaps: designs or images that will be used to make the stage.

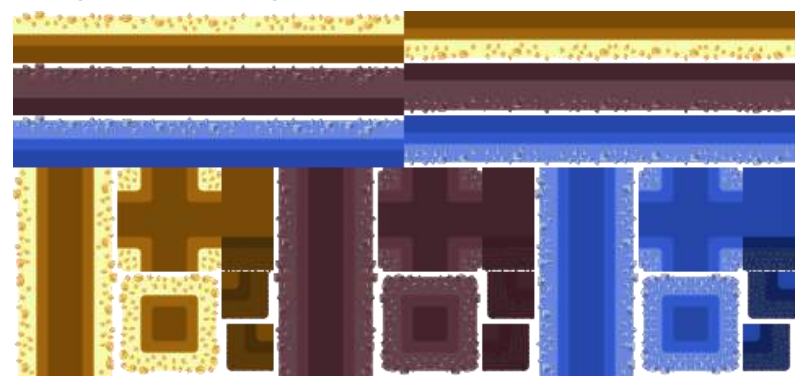

Fig. 9 Display of tilemaps 
JARES, Vol. 4 No. 1 March, 2019; p-ISSN: 2502-826X; e-ISSN: 2503-1163

Copyrights@ Balitar Islamic University, Blitar, Indonesia;

https://ejournal.unisbablitar.ac.id/index.php/jares

Citation: Habibulloh, M., \& Sifaunajah, A. (2019). IMPLEMENTATION OF FOUR

BASIC PHYSICAL LAWS IN THE ADVENTURE GAME "ESCAPE LAND\&quot; JARES (Journal of Academic Research and Sciences), 4(1), 48-54. https://doi.org/10.30957/jares.v4i1.689

4) Obstacle: obstacles that will be faced in the game, there are many kinds of obstacles that are displayed at each different level according to their level.

TABLE I

TyPES OF OBSTACLES IN THE GAME

\begin{tabular}{|c|l|l|}
\hline No. & Picture & \multicolumn{1}{c|}{ Information } \\
\hline 1 & $\begin{array}{l}\text { The Wave Machine is used to } \\
\text { determine the distance by emitting } \\
\text { waves }\end{array}$ \\
\hline 3 & $\begin{array}{l}\text { Gravity is used to move gravity from } \\
\text { top to bottom or vice versa }\end{array}$ \\
\hline 4 & $\begin{array}{l}\text { Canon is used to determine the right } \\
\text { angle so that it reaches the requested } \\
\text { object using the parabolic motion law }\end{array}$ \\
\hline 5 & $\begin{array}{l}\text { The jumper has a spring force that is } \\
\text { used to reflect the player }\end{array}$ \\
\hline 7 & $\begin{array}{l}\text { Spike is an obstacle in the form of } \\
\text { thorns that can eliminate the player }\end{array}$ \\
\hline & $\begin{array}{l}\text { Gunz is an obstacle in the form of } \\
\text { shots that continue to follow the } \\
\text { player with a certain distance }\end{array}$ \\
\hline & $\begin{array}{l}\text { Rock Falling is an obstacle in the form } \\
\text { of objects that fall with a certain } \\
\text { distance passed by the player }\end{array}$ \\
\hline
\end{tabular}

User Interface

1) Initial map display

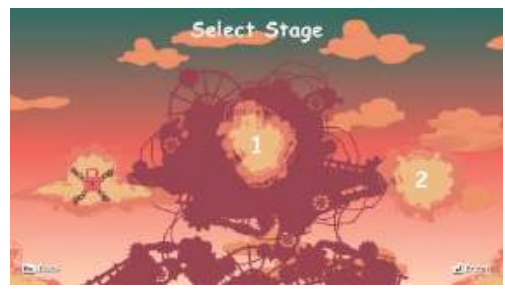

Fig. 10 Display early maps

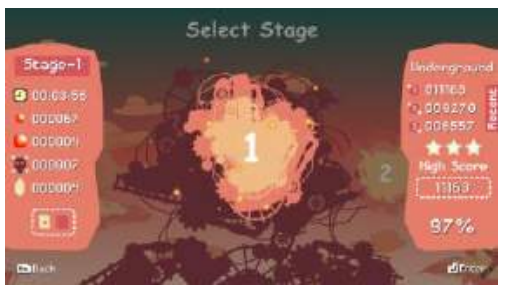

Fig. 11 Display maps with value acquisition 
Citation: Habibulloh, M., \& Sifaunajah, A. (2019). IMPLEMENTATION OF FOUR

BASIC PHYSICAL LAWS IN THE ADVENTURE GAME "ESCAPE LAND\&quot;. JARES (Journal of Academic Research and Sciences), 4(1), 48-54.

2) Display gameplay

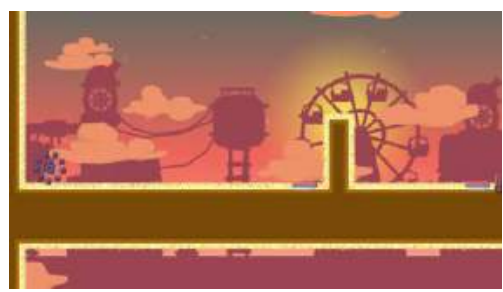

Fig. 12 Display gameplay

\section{DISCUSSION}

\section{A. The Process of Implementing Physics Law}

In this Escape Land game, the author uses some basic laws of physics so that the user doesn't just play, but the user can also get knowledge by playing this game. The physical laws that I use in this game are parabolic motion, gravitational force, wave reflection, and the electromagnetic force.

1) Implementation of parabolic motion: the implementation of parabolic motion occurs when the player enters Canon obstacle, which is a machine that is in the Escape Land game that can catapult players with certain angles and certain speeds.

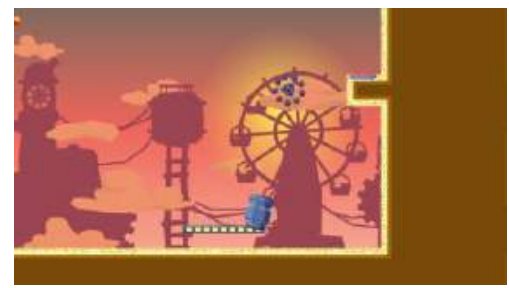

Fig. 13 Implementation of parabolic motion

2) Implementation of gravitational force: occurs when a player touches a gravity machine will result in gravity transfer in the direction of the gravity machine.

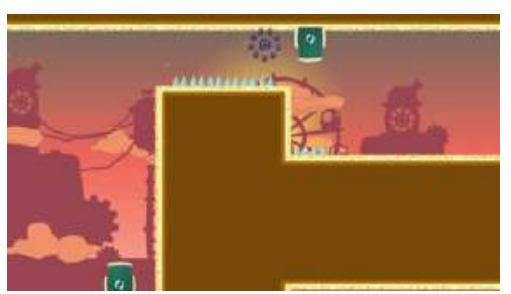

Fig. 14 Implementation of gravity 
3) Wave reflection implementation: The process of implementing wave reflection in the Escape Land game is obtained when the player enters the obstacle wave machine to find the correct path according to the specified clue. To complete this obstacle, the player must know the sound reflection equation which is usually used to measure the depth of the sea, by using $340 \mathrm{~m} / \mathrm{s}$ wave propagation like the following formula.

$$
S=\frac{v \cdot t}{2}
$$

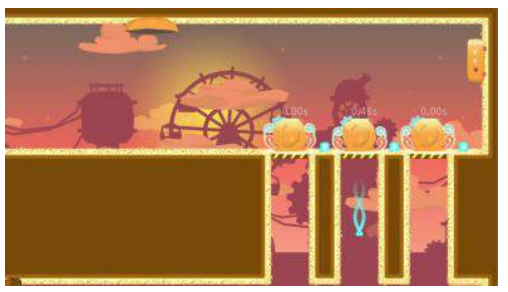

Fig. 15 Implementation of wave reflection

4) Electromagnetic implementation: occurs when a playergets a magnetic item and approaches another item with a certain distance, then the item will be attracted towards the player, but the player's magnetic ability is limited by time.

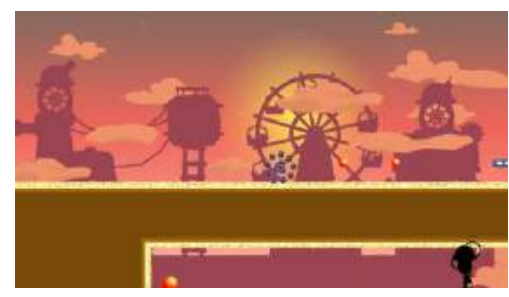

Fig. 16 Electromagnetic implementation

\section{B. User Response Results}

To find out users of the Escape Land game, the authors conducted a system feasibility test. Testing of this system using questionnaires, questionnaires used to collect data from several written questions submitted to respondents. The indicators used in the assessment of this questionnaire are as follows:

1) Ease of operating the Escape Land game

2) User interest in the Escape Land game

3) The functionality of the Escape Land game 
JARES, Vol. 4 No. 1 March, 2019; p-ISSN: 2502-826X; e-ISSN: 2503-1163

Copyrights@ Balitar Islamic University, Blitar, Indonesia;

https://ejournal.unisbablitar.ac.id/index.php/jares

Citation: Habibulloh, M., \& Sifaunajah, A. (2019). IMPLEMENTATION OF FOUR

BASIC PHYSICAL LAWS IN THE ADVENTURE GAME "ESCAPE LAND\&quot; JARES (Journal of Academic Research and Sciences), 4(1), 48-54.

https://doi.org/10.30957/jares.v4i1.689

The instrument used in this study is a questionnaire with a number of questions to the respondent in accordance with predetermined indicators and uses a particular rating scale on each question.

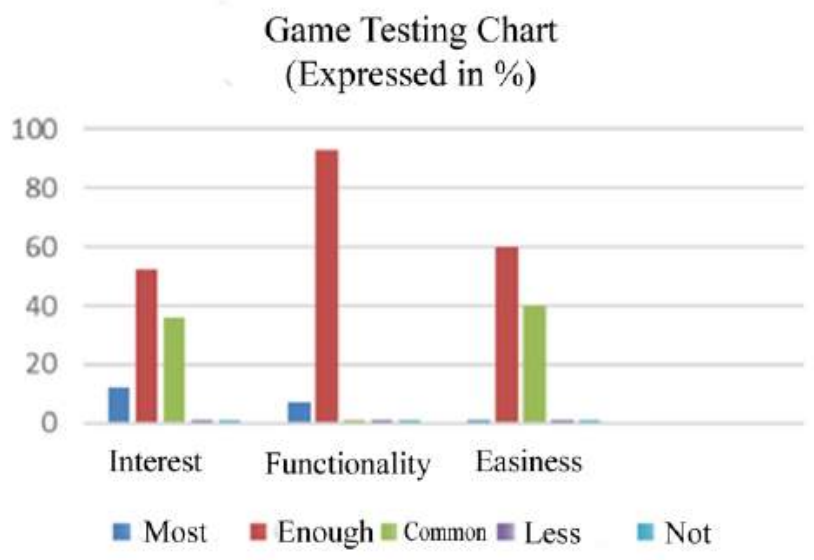

Fig. 16 Graph game testing

Based on the graph above, conclusions can be drawn in terms of the interest in using the game stating that $12 \%$ of respondents were very interested, $52 \%$ of respondents were quite interested, and $36 \%$ were ordinary, in terms of functionality there were around $7.14 \%$ very good, $92.85 \%$ quite good, and the rest normal While in terms of ease of use there is $60 \%$ quite easy, and $40 \%$ of respondents feel normal.

\section{CONCLUSION}

Based on the results of implementation, black box testing, and the results of questionnaires from several respondents, it can be concluded that the Escape Land game is able to implement science related to several physical laws, namely parabolic motion, gravity, magnetism, wave reflection, spring force, collisions, and others. The results of black box testing are correct and there are no error functions on the button and are feasible to implement. Escape Land games can help increase creativity and interest in learning users have been stated to have been achieved because according to the results of the questionnaire distributed to several respondents, $52 \%$ of respondents said they were quite interested in studying the laws of physics. 
JARES, Vol. 4 No. 1 March, 2019; p-ISSN: 2502-826X; e-ISSN: 2503-1163

Copyrights@ Balitar Islamic University, Blitar, Indonesia;

https://ejournal.unisbablitar.ac.id/index.php/jares

Citation: Habibulloh, M., \& Sifaunajah, A. (2019). IMPLEMENTATION OF FOUR

BASIC PHYSICAL LAWS IN THE ADVENTURE GAME "ESCAPE LAND\&quot; JARES (Journal of Academic Research and Sciences), 4(1), 48-54.

https://doi.org/10.30957/jares.v4i1.689

\section{REFERENCES}

[1] F. Gunawan, "Adventure Game Application for Children as a Media for Learning Flora and Fauna in Indonesia," J-Intech Journal of Information and Technology, vol. 3, no. 1, pp. 52-55, 2015.

[2] MR Rahadi, KI Satoto, and IP Windasari, "Designing Game Math Adventure as an Android-Based Mathematics Learning Media," Journal of Computer Technology and Systems, vol. 4, no. 1, 2016.

[3] SN Wahid and AM Kurniawan, "Designing Games for Snakes and Ladders for Media Learning Physics," Journal of Qua Teknika, vol. 7, no. 2, pp. 47-53, 2017.

[4] OA Randle, OO Ogunduyile and NA Fashola, "A Comparison of Performance of Supervised and Unsupervised Machine Learning Techniques in Evolving Awareness / Come on Game Player," International Journal of Game Theory and Technology (IJGTT), p. 1, 2015.

[5] RG Abadi, "Designing Android-based Game Fun with Physic Applications," Negri Alauddin Islamic University, Makassar, 2016.

[6] IGW Antara, IGM Darmawiguna and IMG Sunarya, "Development of Jegog Games Based on Android," National Journal of Informatics Engineering Education (JANAPATI), vol. 4, no. 2, pp. 50-57, 2015.

[7] WN Solehah, "Making Game Application" Habit Education "Based on Android," AMIKOM College of Information and Computer Management, Yogyakarta, 2016.

[8] N. Oktavia, A. Sofia, L. Tyas, NI Khasanah and NR Marfu'ani, "Making Construct 2 Based Educational Games as Physics Learning Media for Junior High School Students," in Proceedings of the National Seminar on Physics and Applications, Jatinangor, 2015.

[9] W. Pratama, "Pandora's Adventure Game Mystery Box," Journal of Telematics, vol. 7, no. 2, pp. 13-31, August 2014.

[10]K. Bashir, "Development of Computer-Based" Phy Detective "Learning Media to Increase Middle School Students' Interest in Learning," Semarang State University, Semarang, 2013.

[11]D. Eridani, PI Santosa and R. Ferdiana, "Implications of 2D and 3D Educational Games: Knowing the Letters and Numbers for Children," JNTETI, vol. 3, no. 1, pp. 1-5, 2014. 